\title{
7
}

\section{Parties Involved}

We grow oyster mushrooms on our partners' coffee grounds. Our partners provide us with a service in return. That could be in the form of products, but other forms are also possible. Brans Oesterzwamkwekerij, www.oesterzwa mkwekerij.nl.

In close collaboration with our stakeholders, we draw up a strategic plan every four years in which we describe how we fulfil our mission. Our strategy is a reflection of the trends we see in society and technology. Dutch National Organization for Applied Research (TNO), www.tno.nl.

The objective of Boekel Energie is to facilitate affordable, sustainable, and locally owned energy for all residents and businesses of the town of Boekel. This initiative, which has representatives from all walks of life, is seeking to set up a local sustainable energy cooperative in the municipality. BoekelEnergie, www.boekel.nl.

At the Windcentrale you become the co-owner of a turbine, with which you generate your own $100 \%$ sustainable wind energy. Everyone can benefit from the efficiency and the green power of wind turbines. Everyone can become a Wind sharer. And by everyone, we really mean everyone. The Windcentrale, www.windcentrale.nl.

DNB (the Dutch National Bank) wants to facilitate and stimulate sustainability in the financial sector and the economy. For that, we actively seek cooperation, for instance in the Sustainable Finance Platform and in the Network of Central Banks and Supervisors for Greening the Financial System (NGFS). This international network aims to make the financial system greener and increase the financial sector's efforts to achieve the Paris climate targets. $D N B$, www.dnb.nl. 
We enable everyone to contribute to a sustainable future by investing in partnerships with new energy producers assisting those who dare to take responsibility and actively commit to creating a better tomorrow. We are also there for the switchers who are looking for new energy at a fair price. Huismerkergie, www.huismerkergie.nl.

New Horizon Material Balance facilitates the dismantling of buildings with the aim of harvesting as many materials as possible for reuse enabling them to supply the largest range of urban mining building materials in the world. New Horizon Material Balance is also the coordinator of the Urban Mining Collective (UMC) which consists of a wide range of partners from the Dutch construction sector, namely: Stiho, Rexel, Elektroned, Knauf, Tétris, JLL, TGN, Wavin, Douveren Brickworks, the Rutte group, NIBE, ABN AMRO, Thinkle, Kingspan Unidek, Spaces4You, Weekamp, Rensa, ZND, and Icopal. New Horizon Material Balance controls the raw material flows within the collective and brings the (joint) innovations to the market. New Horizon newhorizon.nl; Urban Mining Collective, www.urbanminingc ollective.nl.

\subsection{Who Is Participating?}

In this building block, the central question is identifying what actors and stakeholders you want to engage with, work with, or create value for through your business model. As indicated in the previous chapter, identifying the parties that you work with is an essential, or community-based business model. Working together on (multiple) value creation is always a collective task in which value chains and networks take a central position.

The Parties building block addresses the identification and selection of stakeholders that are relevant to the realization and implementation of your business model. It is useful to make an overview of them when designing a business model. In the first place, it is about determining who they are and what interests they have or may have in relation to your business model, which in turn will help to determine what relationship these stakeholders have with your business model. Are they parties you have to deal with immediately as they are essential for your business model to work? Or are they more distant, but ultimately influence the social acceptance of your idea?

Freeman (1984) formulated the notion of stakeholders in relation to organizations. A stakeholder is any person or group of people who have a particular interest in an organization. Stakeholder theory arose in response to the prevailing, restrictive, shareholder perspective. The latter assumes that an 
organization only serves one group of people: the shareholders. Everything that happens within the organization must therefore be to advance or serve the interest of this group of investors. The rationale underlying this approach is that shareholders are the paying party and own the organization. Principalagent theory is central to explaining behaviour within the shareholder view of organizations. The agent (read director, manager, superior) works on behalf of the shareholder (the Principal) and will carry out his or her work within the limits imposed by the Principal. Conversely, the Principal will check the agent's activities and, if necessary, step in to make adjustments.

Stakeholder theory has a broader perspective and considers the shareholder to be just one of a multitude of different stakeholders of an organization. Other stakeholders include customers, employees, local residents, the government, and suppliers. The idea is that not only can shareholders determine what happens within an organization, but that the course of an organization is plotted in consultation with these stakeholders. Some stakeholders are directly involved in decision-making. Other stakeholders are somewhat more distant and do not have a direct say, but do experience (in part) the consequences of decisions made.

Not all groups of stakeholders therefore have the same influence on decision-making. In order to better describe the influence of these groups, Mitchell et al. (1997) distinguish between (1) power, (2) legitimacy, and (3) urgency. Power refers to the degree to which a group of stakeholders can move an organization in a certain direction, through force, seduction, or imaging (Mitchell et al., 1997). Legitimacy addresses the question of to what extent a stakeholder is justified in exerting pressure on an organization, within the existing social context. Finally, urgency relates to the extent to which a stakeholder calls for immediate action (Mitchell et al., 1997). It is important for organizations to determine what each stakeholder's position is with regard to power, legitimacy, and urgency. Only then will it become clear to what extent the interests of the stakeholder concerned must be taken into account in the way in which an organization is managed.

In short, stakeholder analysis consists of identifying the actors and parties that are relevant to the realization and implementation of your business model. Numerous tools have been developed in recent decades to identify parties and determine the nature of their relationship. How you use these tools will depend on what you want to achieve. Do you want to make an initial sketch of your business model, or are you looking for a detailed blueprint? 


\subsection{Identifying People}

In order to determine which actors influence your business model, it is important to identify which parties in your network you will proactively shape the proposition with. There are various ways to portray (potential) partners, such as a traditional stakeholder or chain analysis (Johnson et al., 2017). However, be mindful that these traditional analyses start from an individual organization that creates a value proposition. In contrast, in the BMT we want to get away from the traditional distinction between internal and external stakeholders because a core premise of our BMT is intentionally formulating and organizing the value proposition together.

For these reasons, we suggest that you do a network analysis to determine the parties you want to work with to realize your business model, for example other companies, government departments or agencies, or future users. In network analysis, you identify everyone who is or may be relevant to the business model and indicate the extent to which there is a relationship between you and the identified parties. The actors identified can, of course, be parties from your existing network, or parties that are affiliated with your network and with whom it is relatively easy to establish contact. It could also be that you can only realize your value proposition by entering into a relationship with parties with whom you have no relationship as yet.

We encourage you to keep an open mind and think broadly. Key partners could be the neighbour you do not yet have contact with or a third party in a completely different sector that can purchase or take care of a residual flow from you. In identifying potentially relevant stakeholders, try to get an impression of these potential new partners and more specifically what activities you can organize with them.

There are many ways to carry out a network analysis. It can be done very easily, for example, by firstly identifying the names of actors who are relevant to realizing the value proposition and adding them to Post-its ${ }^{\circledR}$ in a brainstorming session, and secondly, exploring how they are related.

To aid identification of actors in the first step of this process, we highlight three key approaches to mapping networks: (a) Spider Web Model (Fig. 7.1), (b) Mesh Network Model (Fig. 7.2), and (c) Cluster Tree Model (Fig. 7.3).

(a) Spider Web model: Start from your own position where you, as an initiator, set up a partnership and identify the related parties with you in the centre. This is a network model reminiscent of a spider in a web (Fig. 7.1). 


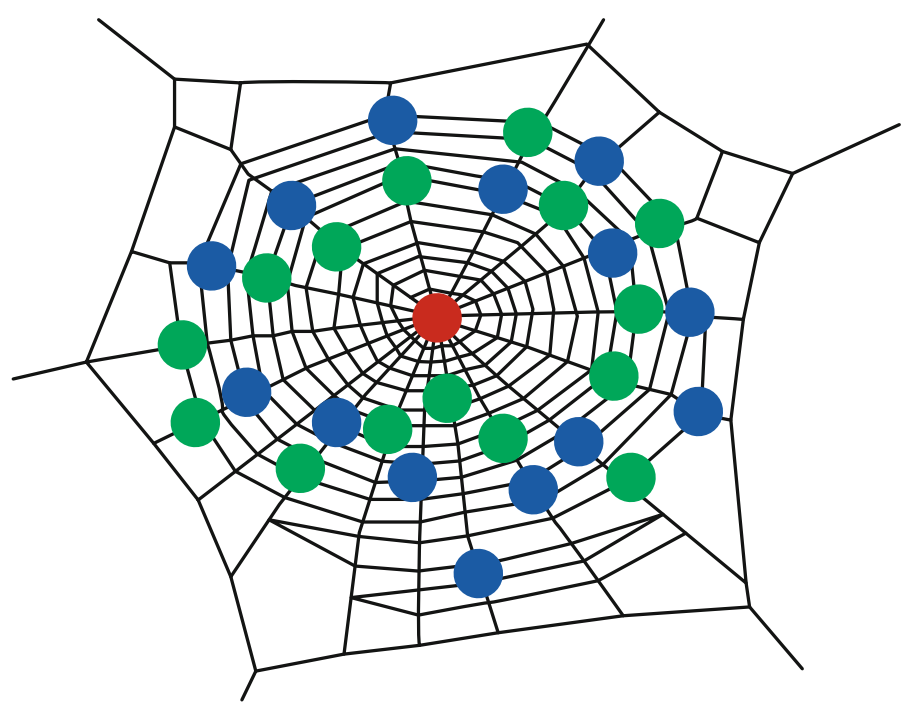

Fig. 7.1 Spider Web model

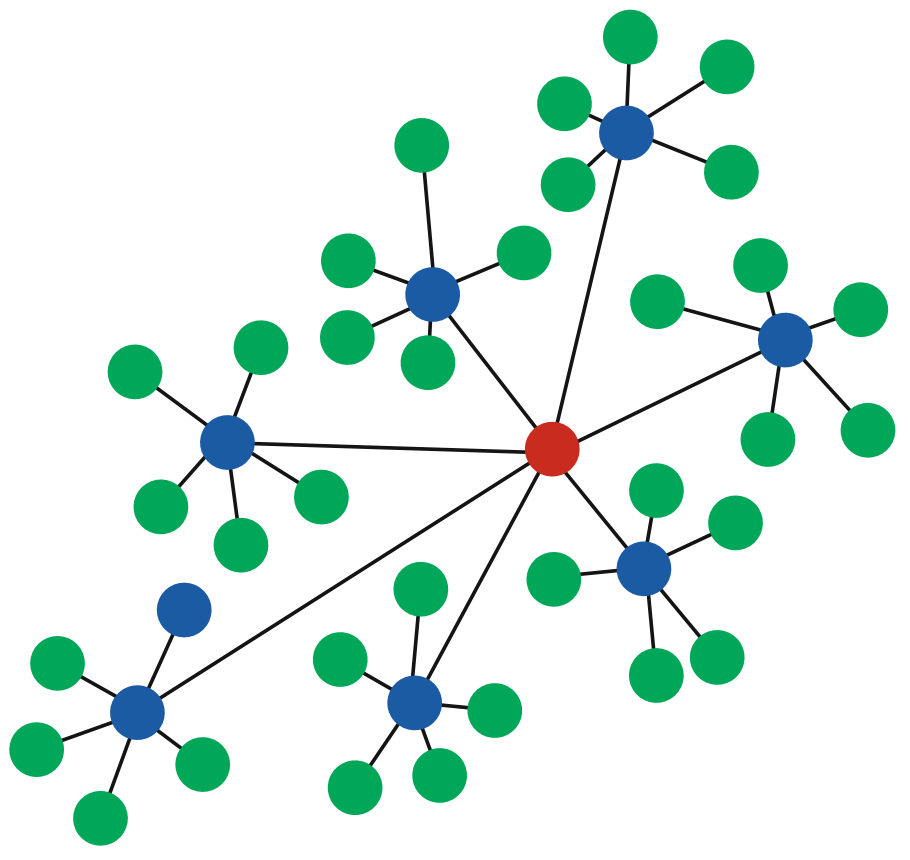

Fig. 7.2 Mesh Network model 


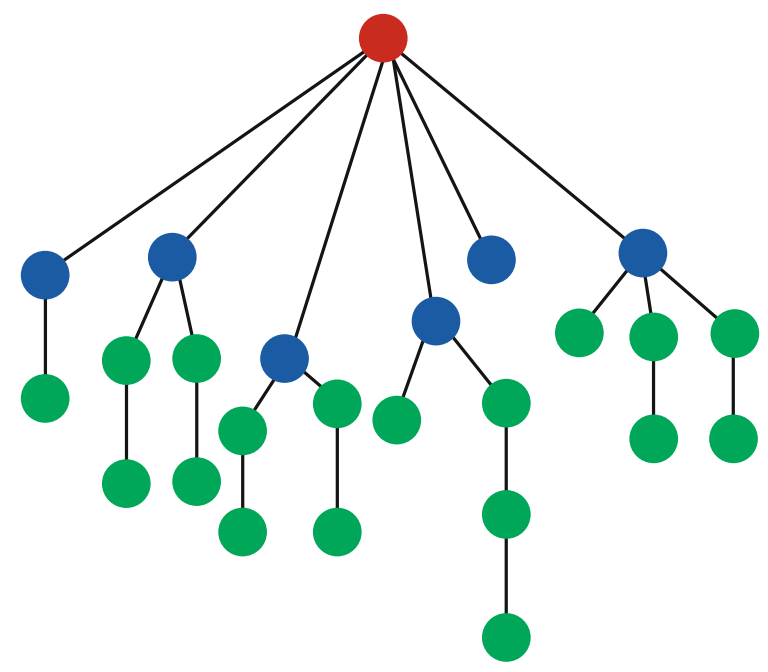

Fig. 7.3 Cluster Tree model

(b) Mesh Network model: When you create a value proposition with multiple parties, a mesh model (Fig. 7.2) is a good starting point. The participating parties are links in networks in which all parties are mutually connected, without a central spider in the web. However, within a broader network of parties, it is important to determine the boundaries of the collective of parties with which you realize the value proposition. This prevents you from losing your perspective.

(c) Cluster Tree model: If you are finding the mesh network approach challenging, it might be beneficial to develop a Cluster Tree Model (Fig. 7.3). Here, you start with yourself as the starting point of the network. What may become evident when you have produced an overview of the network is that you may not be the central point. The BMT is designed intentionally to challenge you to approach everything-including the network analysis-from the combined/multiple actor perspective rather than from just your own or an individual organization's perspective.

The identification of the parties in your network is a first step that serves as the basis for a much more extensive analysis of the interrelationships between different actors. In addition, understanding these interrelationships can enable you to investigate these actors' powers to positively or negatively influence the value proposition. Several methods are available to support these additional analyses. Here we recommend two tools to determine the possible roles and influences of the various stakeholders and parties in your network: 
1. Force field analysis: Once you have mapped your network you can indicate the forces between parties, for example with green and red arrows, addressing the question(s) of how the parties relate to each other and whether they have a positive or negative influence on each other or on your business model idea. This process can provide insight into the roles and interrelationships of the parties and how and whether you might need to align your network to realize your value proposition.

2. Stakeholder value analysis: This is a more extensive method to visualize the current or intended value of transactions for each stakeholder relationship. In a stakeholder value analysis, you indicate what you exchange with the different parties in the network, for example: money, products, services, data, knowledge, reputation, access. The thickness of the arrows can indicate the relative size of the transactions. This gives greater insight into the roles and relationships between the parties involved, and how you can seek to align them. By mapping the interests of stakeholders, you ensure that interests are linked to transactions and value(s) creation. In multi-stakeholder business models, interaction, participation, and collaboration between parties are crucial. Achieving the desired co-creation requires trust, openness, and meaningful engagement between parties.

\section{TIP}

For additional examples of how to perform a force field analysis or a stakeholder analysis, look at businessmodellab.nl/en/tools (Business Model Lab, 2019).

After you have analysed which parties are relevant and how they can contribute to the realization of the goal, you can also consider how and what type of partnerships you want to enter into with these parties. Do you enter into a cooperation agreement with them? Or develop a joint venture together? Or do you set up a cooperative? At all of these key decision points, sensecheck your choice of business model archetype and whether your partnership structure will influence or impact your proposition in any way.

\section{Example}

\section{Developing a Circular Holiday Home}

In the circular economy, new business models are created not only within, but especially between organizations. This has resulted in a spontaneous 
collaboration between four participating parties: a holiday park owner, a contractor, a finishing company, and a demolition company. Together they have developed a circular holiday home. By involving the demolition company in the design process, optimization is achieved in the chain, closed loops are created, and materials are used optimally, for example by making agreements about dimensions of sheet material so that no residual waste remains. As a result, parties not only get new cooperation partners but also share knowledge and acquire new roles in the chain.

\subsection{Case Study: Parties}

\section{Case Study: GreeNet}

GreeNet's dream is to reduce litter produced by train passengers. For this purpose, GreeNet has created and launched the Clean Mobility Initiative (CMI) to change the behaviour of travellers, so that they return their waste at train stations via Reverse Vending Machines (RVM). The GreeNet business model contains a large number of parties. On the one hand, this makes it very strong, but this also brings weaknesses. The network analysis method that is used to list and identify the parties is the spider in the web model.

Figure 7.4 provides an overview of all parties involved in this business model. At the core, there is GreeNet. GreeNet facilitates the CMI and ensures that

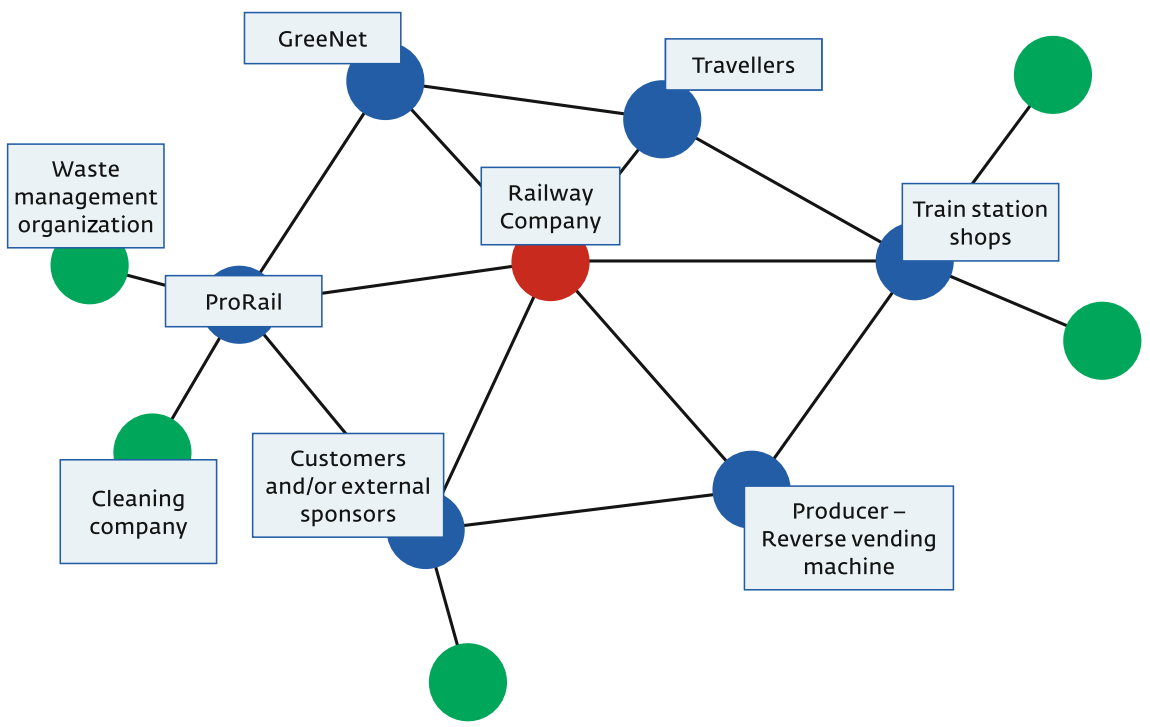

Fig. 7.4 GreeNet Network model 
communication between all stakeholders runs well and that all parties involved do what they have to do. GreeNet is the spider in the web so to speak. Dutch Railways will finance the savings system and the RVM in this business model.

Dutch Railways and ProRail want to create attractive and comfortable railway stations for travellers and other users. A properly functioning cleaning process is an important priority here. The cleaning company Asito is responsible for cleaning services in the north-west and south-west as well as the north-east of the Netherlands. In addition, ICS (another cleaning company) will continue to do the cleaning at a number of the railway stations in the south of the country, with an extension to a number of stations. GreeNet wants to link the savings system to a public transport card. Transnet already has an app for the public transport chip card, so it is a simple step to add functionality by which people can keep track of their credit balance and costs.

In the future, GreeNet would like to collaborate with various stores and facilities available at the various railway stations. One could think of shops, food counters, or toilet facilities such as Sanifair or 2theLoo. The more station stores want to participate in the credit system, the stronger the value of the credits becomes. At these stores and facilities, you could pay with the credits that are linked to your public transport chip card.

We put our trust in the millions of Dutch Railways travellers who will be using the new savings system. When they hand in their plastic bottles and paper cups, they will be able to save the credits using their public transport chip card. In addition, the traveller will unscrew the cap from their PET (polyethylene terephthalate) bottles themselves, lest the bottle be refused by the RVM. A large part of the process will, therefore, be the responsibility of the travellers themselves.

For the collection of waste, a producer of the separation systems is required. It is important that the machine can distinguish which waste is deposited and put it into the correct waste bin. The machine will refuse bottles that are supplied with caps. An RVM can do this. Consequently, the choice of this type of machine was easily made.

In this context, it is also important that there is an extra compartment in the RVM for people to drop their plastic caps into. Immediately after collection, the residual waste will be shredded, so that much more residual waste can be stored in the machine. With this RVM, a monitor or tablet will be provided allowing people to indicate the choice of either price or credits, and on which travellers can scan their public transport chip card. A possible manufacturer of this is Tomra, a company which focuses on the production of this type of collection system.

We give external sponsors the opportunity to provide awards that travellers can get. This is to ensure that the big awards do not have to be financed by Dutch Railways themselves. But of course, we also give Dutch Railways the option to make awards available. We could even have these sponsors contribute to the regular credit value. The advantage for these sponsors is the prestige they get by entering into this collaboration.

After the material has been collected and separated, a lot of plastic bottles, caps, and paper cups remain. These can be picked up by parties who benefit from them. For example, the caps could be delivered to WasteBoards, while the bottles could go to producers such as Coca-Cola. These parties aim to make all drinking bottles circular by 2025 . 


\subsection{The Art of Uniting Parties}

Identifying and understanding the actors or stakeholders that are relevant to the realization and implementation of your business model is pivotal. Defining the interests, influence and interrelationships between the parties in your network primarily helps to determine the necessary connections that must be made in order for your business model to function, and in addition, understanding which stakeholders can play a crucial role in helping you to create a good fit between the business model and its environment. This fit may be necessary to receive the support needed to anchor your business model in the social context and successfully realize its ambitions.

In all of the business model archetypes discussed, it is not always immediately obvious in advance which actors may play a role in creating the necessary supporting context for a business model to thrive. This makes continual reflection on the key stakeholders and their roles in the Parties building block vital because you will need to decide which of your stakeholders you will actively engage to shape and co-create the strategy underpinning your business model. We will discuss this further in the next chapter.

\section{References}

Business Model Lab [Tools]. (n.d.). Retrieved on 20.6.2019 from www.businessm odellab.nl/en.

Freeman, R. E. (1984). Stakeholder management: A strategic approach. Pitman. Johnson, G., Whittington, R., Scholes, K., Angwin, D., \& Regnér, P. (2017). Exploring strategy: Text and cases. 11th edn. Pearson Education Limited.

Mitchell, R. K., Agle, B. R., \& Wood, D. J. (1997). Toward a theory of stakeholder identification and salience: Defining the principle of who and what really counts. Academy of Management Review, 22(4), 853-886. 
Open Access This chapter is licensed under the terms of the Creative Commons Attribution 4.0 International License (http://creativecommons.org/licenses/by/4.0/), which permits use, sharing, adaptation, distribution and reproduction in any medium or format, as long as you give appropriate credit to the original author(s) and the source, provide a link to the Creative Commons license and indicate if changes were made.

The images or other third party material in this chapter are included in the chapter's Creative Commons license, unless indicated otherwise in a credit line to the material. If material is not included in the chapter's Creative Commons license and your intended use is not permitted by statutory regulation or exceeds the permitted use, you will need to obtain permission directly from the copyright holder.

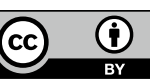

